\title{
Livro de registro de inspetores escolares: fonte de pesquisa para a história da educação regional
}

\author{
Register book of school inspectors: a research source for the history of \\ regional education
}

\author{
Dulcinéia Conceição Ligeiro \\ Mestra em Educação \\ Secretaria Estadual de Educação do Estado de São Paulo - SEE/SP. \\ Taquaritinga, São Paulo - Brasil. \\ dulcineiacligeiro@gmail.com \\ Alessandra David \\ Doutora em Educação Escolar \\ Centro Educacional Moura Lacerda. \\ Ribeirão Preto, São Paulo - Brasil. \\ davidalessandra@uol.com.br \\ Silvana Fernandes Lopes \\ Doutora em Educação \\ Universidade Estadual Paulista - Unesp. \\ São José do Rio Preto, São Paulo - Brasil. \\ sf.lopes@unesp.br
}

Resumo: Este artigo tem como objetivo discutir alguns aspectos do trabalho do inspetor escolar no ensino primário, tomando como fonte os registros dos termos de visitas em um grupo escolar do interior paulista, no período compreendido entre 1931 e 1940. Trata-se de uma pesquisa documental e bibliográfica. A análise dos registros resultou na constatação de que, dentro do ideário da Escola Nova, o que mais se desenvolveu nos grupos escolares foram as instituições assistencialistas, como a Caixa Escolar, e que os inspetores escolares contribuíram para a divulgação do nacionalismo imposto por Getúlio Vargas, assim como para a expansão da escolarização no estado de São Paulo.

Palavras chave: grupo escolar; história da educação; inspetor escolar.

Abstract: This article aims at discussing some aspects of the work of school inspector in primary education, using as source records of the terms of visits in a school group in the interior of São Paulo, in the period between 1931 and 1940. It is a documentary and bibliographic research. The analysis of records resulted in the verification that, within the ideas of Escola Nova, the most developed in school groups were welfare institutions, such as Caixa Escolar, and that school inspectors contributed to the dissemination of the nationalism imposed by Getúlio Vargas, as well as for the expansion of schooling in the state of São Paulo.

Key-words: primary school; history of education; school inspector.

Cite como

(ABNT NBR 6023:2018)

LIGEIRO, Dulcinéia Conceição; DAVID, Alessandra; LOPES, Silvana Fernandes. Livro de registro de inspetores escolares: fonte de pesquisa para a história da educação regional. Dialogia, São Paulo, n. 38, p. 1-14, e19754, maio/ago. 2021. Disponível em: https://doi.org/10.5585/38.2021.19754.

American Psychological Association (APA)

Ligeiro, D. C., David, A., \& Lopes, S. F. (2021, maio/ago.). Livro de registro de inspetores escolares: fonte de pesquisa para a história da educação regional. Dialogia, São Paulo, 38, p. 1-14, e19754. https://doi.org/10.5585/38.2021.19710. 


\section{Introdução}

Dentro da temática proposta para este dossiê - "Modos de fazer e de pensar a História da Educação" -, este artigo tem como objetivo discutir alguns aspectos do trabalho do inspetor escolar no período compreendido entre 1931 e 1940, tomando como objeto de estudo os termos de visita realizados ao Grupo Escolar de Borborema/SP${ }^{1}$.

Essa escola, primeira instituição escolar do município, foi criada por meio do Decreto de 29 de setembro de 1921 e, no período estudado, atendia ao ensino primário.

Ao analisar os termos de visitas dos inspetores escolares, podemos observar o cenário político educacional dessa década. Os inspetores, por meio de suas visitas aos grupos escolares, dedicavam-se ao controle das normas estabelecidas e das atividades pedagógicas, contribuindo, dessa forma, para a execução das políticas públicas.

Do ponto de vista metodológico, há diferentes caminhos possíveis para a investigação da história da educação. Neste artigo, priorizamos uma determinada fonte em uma determinada instituição escolar e em um determinado período histórico.

\footnotetext{
As informações contidas nas fontes servem enquanto contributos para se conhecer o que foi privilegiado em determinado momento histórico, como e o porquê de tais conhecimentos terem sido considerados relevantes, quais métodos e práticas fizeram parte do ideário pedagógico do período em questão e de que forma foram justificadas suas permanências ou ausências do conjunto de conhecimentos trabalhados (MIGUEL, 2013, p. 114).
}

Consideramos essa fonte - os termos de visitas dos inspetores escolares - muito relevante, não somente pela riqueza de informações nela contidas e pela sua originalidade, como também pelo fato de preservar "o tempo em que elas foram produzidas" (PEREIRA; COSTA, 2008, p. 183), ou seja, por refletirem os aspectos socioeconômicos e políticos do período em que os documentos foram redigidos.

A questão fundamental é, então, buscar um conjunto de conhecimentos que possam ser cotejados entre si, procurando uma síntese de múltiplas determinações. Nesse sentido, esta investigação fundamentou-se no método histórico e na análise documental.

Ainda do ponto de vista metodológico, utilizamos categorias de análise construídas com base nos aspectos mais observados pelos inspetores nos termos de visita, tais como a orientação das atividades escolares, a verificação de questões pedagógicas, o acompanhamento da Caixa

\footnotetext{
${ }^{1}$ Este estudo compõe um trabalho de investigação mais amplo, que buscou analisar a atuação do inspetor escolar no período de 1922 a 1966 , por meio de 239 termos de visitas desse profissional.
} 
Escola, aspectos ligados à frequência escolar e à higiene, e a divulgação de políticas de cunho nacionalista.

Este artigo está organizado nas seguintes seções: 1. Uma breve apresentação dos termos de visitas ao Grupo Escolar; 2. Os termos de visitas: relatos de uma profissão; 3. Considerações finais.

\section{Uma breve apresentação dos termos de visitas ao Grupo Escolar}

Os inspetores escolares, em suas visitas às unidades escolares, registravam suas observações e recomendações de próprio punho em um livro destinado especificamente para esse fim, chamado livro de termos de visita. Esse registro formalizava as orientações que deveriam ser seguidas, tanto pelo diretor quanto pelos professores, por ser ele um agente da administração escolar responsável pela fiscalização do ensino, com poderes até mesmo para solicitar sindicâncias em casos de irregularidades. Para cada visita, era redigido um termo com data e assinatura do inspetor.

Esses termos estão em bom estado de conservação e, para tal, a escola recebeu orientações sobre identificação e tratamento de documentos anteriores a 1940, conforme determinação do Decreto no 48.897/2004 (SÃO PAULO, 2004), por meio do Programa de Gestão Documental Itinerante da Secretaria da Educação do Estado de São Paulo. Esse programa considera que os documentos até o ano de 1940 são de guarda permanente, não podendo ser eliminados, mesmo que sejam submetidos a microfilmagem, digitalização ou qualquer outra forma de reprodução. Eles podem ser preservados pelo próprio órgão produtor ou recolhidos ao Arquivo Público do Estado de São Paulo. Nesse caso específico, a escola decidiu manter os documentos em seu arquivo permanente por entender que constituem parte integrante da história da educação da cidade.

Vale ressaltar também que os registros se referem a vários inspetores diferentes. No entanto, o que se pretende mostrar neste artigo não é o trabalho individual dos inspetores, e sim quais eram as principais preocupações desses profissionais em suas visitas às unidades escolares.

Para melhor visualização, apresentamos abaixo um quadro destacando o ano da visita, a quantidade delas, o número de termos existentes ano e ano e seu total na década estudada.

Quadro 1 - Termos de visitas registradas pelos inspetores escolares entre os anos 1931 e 1940.

\begin{tabular}{|l|l|l|}
\hline Anos & Datas dos termos & Total de termos \\
\hline 1931 & $\begin{array}{l}19 / 02,15 / 03,19 / 03,23 / 03,28 / 03,18 / 04,19 / 05,25 / 05, \\
05 / 06,03 / 07,21 / 07,07 / 08,02 / 10,15 / 10\end{array}$ \\
\hline 1932 & $29 / 01,04 / 03,08 / 06$ & 3 \\
\hline 1933 & $24 / 02$ & 1 \\
\hline 1934 & $19 / 07$ & 1 \\
\hline 1935 & $09 / 05,30 / 05,18 / 10,07 / 11$ & 4 \\
\hline 1936 & $27 / 03,02 / 04,17 / 08,17 / 09$ & 4 \\
\hline
\end{tabular}




\begin{tabular}{|l|l|l|}
\hline Anos & Datas dos termos & Total de termos \\
\hline 1937 & $10 / 03,03 / 07$ & 2 \\
\hline 1938 & $29 / 03,14 / 05,02 / 07,12 / 07,22 / 08,26 / 08,14 / 10$ & 7 \\
\hline 1939 & $08 / 03,20 / 04,12 / 07,28 / 08,17 / 10$ & 5 \\
\hline 1940 & $05 / 03,02 / 08$ & 2 \\
\hline Total & & 43 \\
\hline
\end{tabular}

Fonte: Quadro elaborado com base no livro de termos de visitas.

No quadro, é possível verificar uma diminuição das visitas e dos termos ao longo da década. O próprio Anuário do ensino do estado de São Paulo de 1936-1937 (SÃO PAULO, [193?]) relata que a quantidade de inspetores escolares era insuficiente e que, em algumas delegacias de ensino ${ }^{2}$ do interior, havia mais de cinquenta escolas isoladas ${ }^{3}$ atribuídas a cada inspetor, além dos grupos escolares $^{4}$.

Os inspetores escolares recebiam uma verba mensal para cobrir os gastos com as diárias e o transporte em suas visitas. Entretanto, no Anuário (SÃO PAULO, [193?]), há registros de delegados de ensino ${ }^{5}$ sobre a necessidade de aumento dessa verba e reclamações sobre atrasos no pagamento, o que os impedia de fiscalizar as escolas sob sua responsabilidade, uma vez que não tinham "reservas" para as viagens de trabalho.

\section{Os termos de visitas: relatos de uma profissão}

Atendendo às reivindicações dos escolanovistas e ao projeto centralizador do novo governo, em 1931, foram criados o Ministério dos Negócios da Educação e Saúde Pública e o Conselho Nacional de Educação, ambos destinados a garantir diretrizes gerais para a educação nacional.

No Manifesto dos Pioneiros da Educação Nova, em 1932, os reformistas defendiam mudanças na organização educacional, propondo uma escola pública, única, laica, gratuita e obrigatória, e apontavam a falta de espírito filosófico e científico nas resoluções de problemas da administração escolar.

\footnotetext{
21922 a 1966, por meio de 239 termos de visitas desse profissional. As delegacias de ensino eram os locais de trabalho dos inspetores escolares quando não estavam em visitas às unidades escolares. A quantidade de delegacias e a divisão das regionais atendiam às necessidades dos serviços de inspeção, podendo ampliar ou reduzir o número de delegacias conforme os interesses administrativos.

${ }^{3}$ As escolas isoladas eram um tipo de escola primária existente no estado de São Paulo, instaladas em maior número nas zonas ru rais, embora também fossem estabelecidas em zonas urbanas, em bairros mais distantes.

${ }^{4}$ Os grupos escolares ofereciam melhores condições de trabalho aos professores, assim como melhores salários, o que gerava prestígio social aos professores e diretores desses estabelecimentos. Seguiam a organização e a metodologia empregada nas escolas-modelo do estado, ou seja, o que era considerado melhor e mais moderno pedagogicamente.

${ }^{5}$ Os Delegados de Ensino administravam as Delegacias de Ensino e, dentre as muitas funções do cargo, constava também visitar e inspecionar todos os estabelecimentos de ensino subordinados à sua delegacia.
} 
Para os renovadores da Escola Nova no Brasil [...] a reorganização radical do sistema educacional brasileiro passava não apenas pela mudança dos métodos pedagógicos, mas, também, pela finalidade social da escola. Por um lado, cabia a ela adaptar as crianças às necessidades da sociedade moderna, entendida como uma civilização em mudança; por outro lado, ela deveria constituir-se em elemento transformador do meio social, abrindose à comunidade e intervindo nos processos sociais. Dessa maneira, era justificada a relevância das instituições auxiliares da escola - bibliotecas, museus, cooperativas, associações de pais e mestres, caixa escolar, clubes de leitura, assistência médica e dentária, pelotões de saúde, ligas de bondade, entre outras -, e a adoção de um aparelhamento escolar mais sofisticado, incorporando inclusive as novas tecnologias da comunicação (SOUZA, 2013, p. 109).

As ideias escolanovistas influenciaram o Código de Educação do Estado de São Paulo, instituído em 1933 (SÃO PAULO, 1933), e contemplava as instituições escolares com o estabelecimento de serviços técnicos, entre eles, bibliotecas e museus escolares, rádio e cinema educativos, obras sociais escolares, pré-escolares e pós-escolares, visando ao trabalho de cooperação e articulando a ação educativa com o meio social. Entretanto, o ideário da Escola Nova demandou um tempo para sua aceitação e aplicação. Como observamos nos termos analisados, a menção a essas instituições apareceu somente na década de 1940; até então, os inspetores escolares mencionavam apenas a caixa escolar.

Os inspetores, ao verificarem as questões pedagógicas, visitavam as classes, assistiam às aulas, davam instruções para os professores e candidatos ao ingresso no magistério, como no seguinte termo: "no gabinete do Sr. diretor que também estava presente, reuni as senhoras professoras candidatas ao ingresso no magistério com as quais palestrei dando-lhes instrucções sobre o assemptos - Com o Sr. diretor deixei os impressos necessários" (LIVRO DE TERMOS DE VISITAS, 30/05/1935, p. 25).

$\mathrm{O}$ inspetor escolar tanto assistia quanto ministrava algumas aulas em suas visitas, para melhor orientação das atividades escolares. Para verificação do rendimento dos alunos, arguia-os e examinava seus trabalhos gráficos. Nos três primeiros termos do ano de 1936, observou o fraco rendimento dos alunos, como podemos verificar pelos excertos abaixo: 
Percorri quatro classes, em companhia do Sr. Diretor, nas quais assisti e dei aulas, notando que o andeantamento dellas é fraco, motivo pelo qual recommendei ao Prof. XXXX que insistisse junto as Sras. Adjuntas ${ }^{6}$ para que intensificassem o ensino, no sentido de melhorar o adeantamento das classes, afim de que possam ellas acompanhar o respectivo programa. (LIVRO DE TERMOS DE VISITAS, 27/03/1936, p. 26).

Esta visita veio confirmar minha impressão anterior, isto é, de que o adeantamento das classes é fraco, necessitando, porisso, um trabalho intenso dos Srs. Professores para levantar o nível de aproveitamento dos alunnos no corrente exercício. (LIVRO DE TERMOS DE VISITAS, 02/04/1936, p. 27).

Através do trabalho realizado, notei que as classes estão um tanto atrasadas, motivo por que reitero ao Prof. XXXX a recommendação feita a 27 de março ultimo, isto é, que insista junto ao corpo docente do estabelecimento para que seja maior o rendimento escolar. (LIVRO DE TERMOS DE VISITAS, 17/08/1936, p. 27).

Sobre o problema do rendimento escolar, Souza (2009) aponta que, no ano 1936, os delegados de ensino reuniram-se para discutir o baixo rendimento dos alunos e indicaram medidas para reverter o quadro. Porém, os administradores educacionais atribuíam esse problema às técnicas de ensino, à assiduidade de professores e de alunos e à imaturidade e à saúde dos alunos, ou seja, as causas desse problema estariam relacionadas aos papéis desempenhados pelos professores e pelos alunos, não especificamente ao programa educacional e se esse realmente atendia às especificidades do alunado.

Isso aumentava a responsabilidade do inspetor escolar, pois os delegados de ensino entendiam que, nos locais em que o inspetor escolar desempenhava bem o seu trabalho, o resultado era melhor. Souza (2009) apresenta o relato de um delegado de ensino creditando o bom resultado obtido em sua região aos inspetores escolares, que fizeram mais reuniões pedagógicas que as determinadas, exigiram o preparo diário das lições em cadernos apropriados e examinaram o diário das lições em cada reunião, fator que pode justificar a preocupação do inspetor escolar em verificar os diários e semanários nos termos de visitas aqui estudados.

Os professores registravam seus planos de aulas nos diários e semanários, que por isso eram utilizados como controle do trabalho docente. Com o tempo, passaram a servir como formação docente em trabalho, pois os professores novos, menos experientes, copiavam os diários e semanários dos professores mais conceituados (SOUZA, 2004).

Em 1937, ocorreu a instalação do Estado Novo. Segundo Andreotti (2010, p. 110), “no contexto do Estado Novo, a formação escolar teve como eixo ideológico o nacionalismo, o patriotismo e a difusão dos princípios do projeto político-ideológico do governo". Assim, a escola foi utilizada pela máquina estatal para divulgar o ideário do governo e cultuar a imagem de Getúlio Vargas.

\footnotetext{
${ }^{6}$ Professoras adjuntas eram as professoras com classes atribuídas, o número de adjuntas correspondia ao número de classes; havia também as substitutas efetivas, que a elas cabiam fazer estágio de prática de ensino e substituir as adjuntas em suas faltas ou impedimentos. (DECRETO 5.884, 1933, SÃO PAULO, art. 275).
} 
Nesse contexto, em termo de 1938, o inspetor recomendou caráter solene à comemoração de Sete de Setembro, estando, desse modo, em ação a ideologia nacionalista pregada por Vargas. No ano de 1939, solicitou a confecção de pastas de cartão com os respectivos patronos e suas biografias, que deveriam ser bem explicadas aos alunos, além de trabalhos escritos sobre as datas comemorativas passadas e futuras para serem guardados nas pastas dos alunos, e uma pesquisa sobre brasileiros ilustres, que poderia ser um trabalho colaborativo entre os alunos de diversas salas.

Visando à melhoria do rendimento escolar, as questões pedagógicas mereciam atenção constante dos inspetores escolares em suas visitas ao grupo escolar, como exemplifica o trecho do documento a seguir:

Ainda com as senhoras adjuntas ${ }^{7}$ tive ocasião de conversar sobre a organização dos respectivos semanarios, que devem ser ilustrados, trazerem planos e esquemas de aulas, apresentar a devida auto-critica, não devendo os mesmos serem apenas um registro de lições. (LIVRO DE TERMOS DE VISITAS, 08/03/1939, p. 32).

Por essas instruções, podemos inferir que o inspetor escolar interferia na prática pedagógica em termos de inovação e de concepções escolanovistas. No mesmo ano de 1939, o inspetor recomendou ao diretor que, para as reuniões pedagógicas mensais, fosse designada uma professora adjunta ${ }^{6}$ para tratar de assuntos pedagógicos. O inspetor também recomendava o cumprimento da orientação já apresentada ao diretor de que a escola ministrasse conteúdos cívicos, especificamente os hinos pátrios, educação física e trabalhos manuais.

Com esse tipo de orientação e fiscalização, os inspetores escolares colaboravam para a disseminação do projeto nacionalista governamental, tais como a formação do cidadão e do trabalhador por meio da educação moral e cívica, dos bons costumes e do desenvolvimento de aptidões físicas e manuais.

Conversei com os professores sobre a execução do programa, tendo-lhes recomendado que todas as matérias devem ter o mesmo desenvolvimento, com o mesmo carinho e entusiasmo. $[\ldots]$

Entre outras recomendações, deixo as seguintes, que deverão ter o devido cumprimento: a) desenvolver em todas as classes o ensino dos hinos patrióticos; b) determinar a todas as professoras que, diariamente, façam uma preleção sobre o proximo recenseamento; c) dar a Bandeira Nacional o devido culto; [...] e) dar duas aulas modelo, por semana, devendo as mesmas constarem na coluna das observações dos livros de chamada; [...] g) ter sempre à vista a circular de setembro sobre as instruções às autoridades escolares; $h$ ) iniciar, desde já, o preparo da proxima festa de 7 de setembro, que deve ser comemorada condignamente neste estabelecimento de ensino. [...] (LIVRO DE TERMOS DE VISITAS, 02/08/1940, p. 35).

\footnotetext{
${ }^{7}$ Professoras adjuntas eram as professoras com classes atribuídas, o número de adjuntas correspondia ao número de classes; havia também as substitutas efetivas, que a elas cabiam fazer estágio de prática de ensino e substituir as adjuntas em suas faltas ou impedimentos. (DECRETO 5.884, 1933, SÃO PAULO, art. 275).
} 
É perceptível que, atendendo aos interesses do Estado Novo, as atividades escolares eram impregnadas de ideais cívicos e patrióticos. Cabia ao inspetor escolar fiscalizar sua execução e fazer com que diretores e professores acatassem às circulares contendo regras, normas e orientações expedidas pelo Departamento da Educação.

Os inspetores escolares apontavam, em seus termos, a quantidade de alunos matriculados e presentes nos dias visitados e recomendavam a melhoria da frequência dos alunos quando entendiam que ela estava baixa. Em 1931, em um dos termos, o inspetor transcreveu o telegrama do delegado de ensino da região enviado à inspetoria, o qual recomendava um número maior de matrículas e maior frequência dos alunos: "não basta matricula [...], mas melhor matricula e frequência possíveis. Matricula e frequência são dados de grande importância para classificação por merecimento de professor e diretor" (LIVRO DE TERMOS DE VISITAS, 21/07/1931, p. 22).

De fato, o artigo 182 do Decreto no 4.600 (SÃO PAULO, 1929) já tratava da questão da classificação por merecimento, pela qual os docentes melhoravam sua classificação entre os pares, de acordo com o número de alunos matriculados. Tal classificação era importante tanto para a atribuição de classes quanto para a remoção, objetivo de muitos professores que lecionavam fora de seus municípios de origem.

O Decreto no 3.356, de 31 de maio de 1921 (SÃO PAULO, 1921), determinava o ensino primário obrigatório para crianças de 9 e 10 anos, depois reforçado e ampliado pela Constituição de 1934. Assim, estava entre as incumbências dos inspetores escolares o acompanhamento da frequência dos alunos, podendo estes questionar os pais sobre o motivo das ausências e providenciar a matrícula de alunos analfabetos dessa idade. No entanto, ficavam isentas de frequentar a escola crianças que residissem em distâncias superiores a dois quilômetros da escola, que não conseguissem vagas na escola próxima, que sofressem de incapacidade física ou mental, de alguma doença contagiosa, que não tivessem vestuário adequado e que recebessem instrução primária em suas casas ou em instituições particulares.

Somente a partir de 1930 ganhou força a criação de instituições assistenciais dentro dos grupos escolares para o fornecimento de roupas e materiais escolares aos alunos necessitados, visando à expansão da matrícula escolar e à diminuição da evasão e da frequência irregular dos alunos de baixo poder aquisitivo. Quanto às crianças com deficiência física ou mental, e mesmo as portadoras de doenças contagiosas, ainda não havia a preocupação em incluí-las.

Bencostta (2005, p. 74), ao analisar mais especificamente a situação dos grupos escolares no estado do Paraná, aponta que: 
[...] A intermitência na assiduidade foi uma constatação que a escola teve que admitir ao não conseguir manter em suas carteiras aqueles alunos pertencentes às camadas sociais economicamente desfavoráveis, quando suas famílias os convocavam para tarefas domésticas e/ ou remuneradas no mesmo horário dos estudos escolares. Coube aos Estados, através de suas legislações, instaurar dispositivos que estabelecessem de modo impositivo a obrigatoriedade de ensino às crianças em idade escolar, não tendo sido incomum ameaças de punição aos pais que descumprissem tais determinações. Contudo, as determinações legais dificilmente conseguiram assegurar, pela obrigatoriedade do ensino, a almejada regularidade na frequência.

Dessa forma, os motivos socioeconômicos eram determinantes para a frequência escolar, e como a frequência irregular era vista como empecilho para a consolidação dos propósitos educacionais, as ações assistencialistas ganharam força, em uma tentativa de manter o alunado mais carente nos bancos escolares. Os inspetores acompanhavam a quantidade de matrículas e de alunos presentes, mesmo porque o próprio crescimento urbano exigia uma demanda maior de matrículas, assim como a pressão de alguns setores da sociedade que defendiam a importância da alfabetização para o desenvolvimento do país.

Em relação à assiduidade do professor, no ano de 1934, o inspetor registrou que a escola funcionou durante o primeiro semestre com apenas duas classes por falta de professor; a partir do segundo, funcionou com sete classes, apesar da licença de uma professora adjunta, cuja classe estava com uma substituta efetiva. No terceiro termo do ano de 1938, verificou que apenas quatro das oito classes funcionavam com regularidade em razão da falta das professoras adjuntas que ainda não tinham retornado das férias recém-terminadas. Muito provavelmente residiam em outras localidades e, em decorrência das dificuldades de transporte, acabaram perdendo dias letivos.

Pelo artigo 718 do Decreto no 5.884, de 21/04/1933, o ano letivo das escolas primárias iniciava-se em $1^{\circ}$ de fevereiro e encerrava-se em 30 de novembro, com férias de inverno de 16 a 30 de junho. O próprio Anuário do ensino do estado de São Paulo: 1936-1937 (SÃO PAULO, [193?]) citava que as professoras procuravam "fugir" dos bairros para as cidades, e das cidades pequenas para os grandes centros urbanos em virtude das dificuldades que encontravam para adaptar-se ou pela dificuldade para encontrar uma pensão confortável e condizente com seus vencimentos. Todas essas situações afetavam diretamente o funcionamento das classes.

Os inspetores também examinavam os livros de escrituração em suas visitas, demonstrando preocupação com a organização dos documentos escolares.

No primeiro termo do ano de 1935, o inspetor anotou atraso de registro nos livros de expediente e de carga e descarga, registrou o saldo da caixa escolar (157\$300) depositado na Coletoria Estadual e relatou conversa com o diretor sobre as escolas isoladas, uma vez que o diretor do Grupo Escolar era também auxiliar de inspeção no município e a escola era vinculadora de 
escolas isoladas. "Conversei com o Sr. Diretor e aux. insp. sobre as escolas isoladas e verificamos a situação e localização das novas unidades no município. Solicitei do Sr. aux. organização completa dos archivos das escolas isoladas" (LIVRO DE TERMOS DE VISITAS, 09/05/1935, p. 25).

No ano de 1938, aparecem referências às condições físicas do prédio escolar. No primeiro termo, o inspetor visitou todas as dependências do prédio e deu recomendações do ponto de vista higiênico; no segundo, pediu para que o diretor exigisse mais dos serventes, pois a higiene do prédio deixava a desejar. Já no quarto termo, observou a superlotação das classes e a necessidade de criação de mais duas para atender à quantidade de candidatos à matrícula. Assim, no sexto termo, combinou com o diretor medidas para a construção de um prédio escolar.

\footnotetext{
Combinei com o senhor diretor as medidas preliminares a serem tomadas para se levar a efeito a construção de um prédio escolar nesta localidade, aproveitando-se a boa vontade do sr. XXXX, que se propõe construir aqui o prédio para o funcionamento deste estabelecimento. Estive em companhia do sr. diretor em casa do Sr. XXXX, onde, na sua ausência, deixei, com seu filho, as instruções necessárias, sobre esse assunto. (LIVRO DE TERMOS DE VISITAS, 14/10/1938, p. 31).
}

Dados apresentados no Anuário do ensino do estado de São Paulo: 1935-1936 (SÃO PAULO, [193?] apud SOUZA, 2009, p. 142) comprovam que a maioria dos prédios escolares não pertenciam ao estado: "Em 1936, havia 607 grupos no estado, desses apenas um terço, 207 escolas, pertenciam ao Estado e haviam sido especialmente edificadas para esse fim". E mais: "verificado, pelo Governo do Estado, que, após quinze annos de inactividade quasi completa, no tocante a edificações de escolas primarias, São Paulo precisa construir immediatamente mais de duzentos grupos escolares". Ou seja, o déficit era grande e de difícil solução, devido ao crescente aumento da demanda escolar.

Como confirmação das condições em que se encontrava o prédio escolar aqui estudado, o mesmo Anuário cita o relatório do delegado de ensino de São Carlos, a cuja delegacia pertencia o grupo escolar de Borborema, que classificava esse prédio entre os regulares e sofríveis de sua jurisdição. Por esses relatos, concluímos que as precárias condições do prédio escolar afetavam diretamente o desenvolvimento das atividades escolares e impediam o atendimento de um maior número de alunos em razão da falta de espaço, o que explica a grande preocupação dos inspetores em relação a ele.

Em relação aos aspectos de higiene, em 1939, no primeiro termo o inspetor escolar tomou as seguintes medidas: 
[...] Ainda nas classes falei diretamente aos alunos sobre a necessidade do uso do uniforme, da caneca individual e do guardanapo para lanches e recomendei às professoras que façam diariamente a revista e que não percam as oportunidades para darem noções de higiene a seus alunos.[...]

Ao senhor diretor recomendei [...] que proceda, com urgência, a vacinação de todos os alunos contra a varíola e que envie a respectiva relação dos vacinados à Delegacia. [...] (LIVRO DE TERMOS DE VISITAS, 08/03/1939, p. 32).

Com isso, a escola tentava criar hábitos de higiene na população, por meio dos alunos, ao tentar combater antigos costumes, propagar a vacinação e, assim, promover a prevenção de doenças.

A preocupação com a assistência escolar era uma constante. Isso porque as dificuldades econômicas dos pais dos alunos eram vistas como prejudiciais à frequência deles às aulas, pois não conseguiam comprar materiais e uniformes. Entretanto, Souza (2009, p. 250) afirma que os serviços de assistência se prestavam também “[...] aos incontroláveis desejos de intervenção, moralização e disciplinarização da população pobre dos bairros urbanos ou das zonas rurais". De certa forma, era uma maneira de controlar as camadas sociais mais populares.

De todo modo, a caixa escolar fazia-se necessária para o atendimento dos alunos carentes, e o seu saldo era constantemente acompanhado pelos inspetores em suas visitas. Em 1934, o inspetor anotou um saldo de $20 \$ 000$. No segundo termo de 1939 , registrou um saldo de $799 \$ 000$ recolhido na Coletoria Estadual e determinou ao diretor providências para a eleição da nova diretoria da caixa de acordo com a circular de 8 de junho, sendo que a escrituração deveria seguir os modelos existentes no Ato de 30 de outubro de 1934, o qual deu nova organização às caixas escolares. No terceiro termo desse mesmo ano, anotou um saldo de $849 \$ 900$ e solicitou a organização da Cooperativa Escolar, que tinha o propósito de vender algumas mercadorias dentro da escola para arrecadar fundos. Na quarta visita, encontrou a caixa escolar reorganizada de acordo com as instruções e com saldo de $982 \$ 500$.

Em 1940, o inspetor voltou a recomendar ao diretor providências para que fosse fundada a Cooperativa Escolar, pois necessitavam de recursos para comprar com urgência o material a ser fornecido aos alunos. No primeiro termo, anotou um saldo de $916 \$ 400$ na caixa escolar e, no segundo, de 525\$000, informando pela primeira vez que o saldo estava recolhido na Caixa Econômica local, e não mais na Coletoria Estadual.

As instituições escolares ou auxiliares foram instituídas pelo Código de Educação do Estado de São Paulo de 1933 e atendiam ao ideário escolanovista de desenvolvimento da aprendizagem por meio da experiência e do contato com o meio social. Entre essas instituições, estavam as que desenvolviam o espírito de cooperação e assim angariavam fundos para o auxílio a 
alunos carentes. Ou seja, tornaram-se instituições assistencialistas, como a Caixa Escolar e a Cooperativa Escolar.

\begin{abstract}
Entre as instituições auxiliares da escola, a de ação social e a de assistência escolar foram as que mais se desenvolveram nos estabelecimentos de ensino público do estado de São Paulo. Aos poucos, a finalidade educativa de aproximar a escola do meio converteu-se na necessidade do apoio da sociedade para suprir carências das instituições e dos escolares. (SOUZA, 2009, p. 249-250).
\end{abstract}

As instituições escolares de apoio assistencialista logo ganharam importância, pois colaboravam para a frequência dos alunos carentes por fornecer calçados, uniformes e material escolar. Sem a ajuda dessas instituições, ficava difícil manter esses alunos nos bancos escolares. As demais instituições, conforme os termos analisados, acabaram sendo implementadas mais tarde, após 1940.

\title{
3 Considerações finais
}

A análise dos registros dos termos permitiu a constatação que o ideário da Escola Nova demorou para ser absorvido pelo grupo escolar em questão, sendo o que mais se desenvolveu e mais citado nos termos, foram as instituições assistencialistas como a Caixa Escolar.

Durante o Estado Novo (1937-1945), foi instaurada uma política não somente industrialista, mas também nacionalista. Assim, a inspeção escolar estava a serviço da divulgação desse nacionalismo imposto por Getúlio Vargas. O estado de São Paulo, em consonância com a política federal, praticou um programa educacional voltado para a valorização dos símbolos e dos vultos nacionais. E, para demonstrar todo esse sentimento nacionalista, verificamos que os inspetores escolares recomendavam as comemorações das datas nacionais e os desfiles cívicos.

Entretanto, pelos termos analisados, observamos que foram os aspectos pedagógicos e de frequência escolar que tiveram maior atenção dos inspetores escolares. Após o governo de Getúlio Vargas (1930-1945), houve uma mudança nos rumos da economia, com uma política voltada para o desenvolvimento industrial, e não apenas agroexportador. E foi justamente o estado de São Paulo, o berço desse desenvolvimento industrial; por isso a preocupação maior com a escolarização, pois era preciso atender à demanda das indústrias e, consequentemente, do crescimento urbano. Assim, a atuação dos inspetores escolares foi relevante na expansão e no desenvolvimento do ensino primário nos grupos escolares estaduais paulistas. 


\section{Referências}

ANDREOTTT, A. L. A administração escolar na Era Vargas (1930-1945). In: ANDREOTTI, A. L.; LOMBARDI, J. C.; MINTO. L. W. (Orgs.). História da administraşão escolar no Brasil: do diretor ao gestor. Campinas: Alínea, 2010. p. 103-123.

BENCOSTTA, M. L. A. Grupos escolares no Brasil: um novo modelo de escola primária. In: STEPHANOU, M.; BASTOS, M. H. C. (Org.). Histórias e memórias da educação no Brasil. século XX. Petrópolis: Vozes, 2005. p. 68-76.

LIVRO DE TERMOS DE VISITAS (1922-1966). Escolas Reunidas de Borborema/SP. Não publicado.

MIGUEL, M. E. B. História, Memória e Instituições Escolares no Paraná. In: SILVA, J. C. et alii. (Orgs). História da educação: arquivos, instituições escolares e memória histórica. Campinas: Editora Alinea, 2013. p. 113-130.

PEREIRA, G. A.; COSTA, N. M. V. N. O estudo de caso: alternativa ou panacéia? In: BIANCHETTI, L.; MEKSENAS, P. (Org.). A trama do conhecimento: teoria, método e escrita em ciência e pesquisa. Campinas: Papirus, 2008. p. 169-189.

SÃO PAULO (Estado). Decreto n. 3.356, de 31 de maio de 1921. Regulamenta a Lei no 1.750, de 8 de dezembro de 1920, que refôrma a Instrução Publica. Disponível em: https://www.al.sp.gov.br/repositorio/legislacao/decreto/1921/decreto-3356-31.05.1921.html. Acesso em: 20 mar. 2021.

SÃO PAULO (Estado). Decreto n. 4.600, de 30 de maio de 1929. Regulamenta as leis ns. 2.269, de 31 de dezembro de 1927, e 2.315, de 31 de dezembro de 1928, que reformaram a Instrucção Publica do Estado. Disponível em:

https://www.al.sp.gov.br/repositorio/legislacao/decreto/1929/decreto-4600-30.05.1929.html. Acesso em: 20 mar. 2021.

SÃO PAULO (Estado). Decreto n. 5.884, de 21 de abril de 1933. Institue o Codigo de Educação do Estado de São Paulo. Disponível em:

https://www.al.sp.gov.br/repositorio/legislacao/decreto/1933/decreto-5884-21.04.1933.html. Acesso em: 20 mar. 2021.

SÃO PAULO (Estado). Anuário do ensino do estado de São Paulo: 1936-1937. Organizado pelo Prof. A. Almeida Junior, director do ensino, e abrangendo o ensino primario e pre-primario estadual, municipal e particular, o ensino secundário estadual e o ensino normal, estadual e livre. [S.l.]: Tip. Siqueira, [193?].

SÃO PAULO (Estado). Decreto n. 48.897, de 27 de agosto de 2004. Dispõe sobre os Arquivos Públicos, os documentos de arquivo e sua gestão, os Planos de Classificação e a Tabela de Temporalidade de Documentos da Administração Pública do Estado de São Paulo, define normas para a avaliação, guarda e eliminação de documentos de arquivo e dá providências correlatas. Disponível em: https://www.al.sp.gov.br/repositorio/legislacao/decreto/2004/decreto-48897-27.08.2004.html . Acesso em: 20 mar. 2021. 
SOUZA. R. F. de. Lições da escola primária. In: SAVIANI, D. et al. (Orgs.). O legado educacional do século XX no Brasil. Campinas: Autores Associados, 2004. (Coleção Educação Contemporânea).

SOUZA. R. F. de. Alicerces da pátria: história da escola primária no Estado de São Paulo (18901976). Campinas: Mercado de Letras, 2009. 407 p.

SOUZA. R. F. de. Objetos de ensino: a inovação pedagógica e material da escola primária no Brasil, no século XX. Educar em Revista, Curitiba, n. 49, p. 103-120, jul.-set. 2013. 